\title{
PENYIAPAN LANTAI BALAI KAMPUNG, KEMBANG KUNING MULYO KOTA SURABAYA
}

\author{
Desrina Yusi Irawati ${ }^{1}$, Dhita Widya Astanti ${ }^{2}$ \\ ${ }^{1,2}$ Program Studi Teknik Industri, Universitas Katolik Darma Cendika \\ ${ }^{1}$ desrina.yusi@gmail.com* \\ 2patriciadhitawidyaastanti@gmail.com
}

\begin{abstract}
This community service activity was carried out in RT $16 R W 6$, Kembang Kuning Mulyo, Surabaya. This area is an urban village area with poor public facilities. The result of the situation analysis in the area is that Balai RT 16 suffered some damage with conditions that were unfit for use. One of them is that some of the room floors in Balai RT 16 are still in the form of cracked and perforated cement floors. Then the solution offered based on priority problems and the intensity of its use is the installation of advanced floor tiles in the inner room and terrace of Balai RT 16. Implementation of floor tile installation is carried out by teams, RT managers, and residents who have expertise in carpentry. Community service activities are fully supported by the community as evidenced by the participation of residents in the installation of ceramics and their understanding to help maintain the better condition of the Balai RT 16. Since the installation of ceramics, the floor of Balai RT 16 looks cleaner, suitable for use, strong, and not damp.
\end{abstract}

Keywords: Balai RT, installation of floor tiles, clean floor

\begin{abstract}
Abstrak: Kegiatan pengabdian masyarakat ini dilakukan di RT 16 RW 6, Kembang Kuning Mulyo, Surabaya. Daerah ini merupakan daerah desa perkotaan dengan fasilitas umum yang buruk. Hasil analisis situasi di daerah tersebut adalah bahwa Balai RT 16 mengalami kerusakan dengan kondisi yang tidak layak untuk digunakan. Salah satunya adalah beberapa lantai ruangan di Balai RT 16 masih berupa lantai semen yang retak dan berlubang. Kemudian solusi yang ditawarkan berdasarkan masalah prioritas dan intensitas penggunaannya adalah pemasangan ubin lantai canggih di ruang dalam dan teras Balai RT 16. Implementasi pemasangan ubin lantai dilakukan oleh tim, pengelola RT, dan warga yang memiliki keahlian dalam pertukangan. Kegiatan pengabdian masyarakat didukung penuh oleh masyarakat yang dibuktikan dengan partisipasi warga dalam pemasangan keramik dan pemahaman mereka untuk membantu menjaga kondisi Balai RT 16 yang lebih baik. Sejak pemasangan keramik, lantai Balai RT 16 terlihat lebih bersih. , cocok untuk digunakan, kuat, dan tidak lembab.
\end{abstract}

Kata kunci: Balai RT, pemasangan ubin lantai, lantai bersih

\section{Pendahuluan}

Berkembangnya kota tidak terlepas dari bertumbuhnya penduduk. Pertumbuhan penduduk disebabkan adanya arus urbanisasi penduduk dari desa ke kota. Kota-kota besar salah satunya adalah Surabaya, ditempati oleh pemukiman tidak terencana yang seringkali dinamakan kampung. Kampung kota merupakan sebuah sistem permukiman pedesaan, mewakili suatu budaya permukiman pedesaan, mewakili suatu budaya bermukim, memberi corak dan aktifitas khas perkotaan tersendiri yang berkaitan dengan konsep survival terhadap kultur moderen perkotaan disekitarnya (Eko
Budiharjo, 1997). Menurut Turner T., J. (1985) kampung merupakan kawasan permukiman kumuh dengan ketersediaan sarana umum buruk atau tidak ada sama sekali, kawasan ini disebut "slum" atau "squatter". Umumnya di kampung membutuhkan tempat berkumpul warga untuk beraktifitas bersama, musyawarah, berkesenian dan menjadi ruang serba guna. Tempat tersebut seringkali disebut sebagai balai pertemuan. Balai pertemuan adalah gedung tempat berapat, mengadakan resepsi pernikahan, dan sebagainya (KBBI, 2019).

Kembang Kuning Mulyo RT 16 RW 6 Kelurahan Pakis, Kecamatan 
Sawahan merupakan salah satu wilayah perkampungan di Kota Surabaya bagian selatan. Perkampungan ini berada di kawasan sekitar makam Kembang Kuning. Menurut keterangan dari ketua RT 16, kampung Kembang Kuning Mulyo RT 16 terdiri dari $148 \mathrm{KK}$, dengan jumlah lakilaki sebanyak 191, perempuan sebanyak 144. Jumlah anak-anak di kampung ini kurang lebih 50 anak. Warga laki-laki mayoritas bekerja sebagai tukang, buruh lepas pembersih makam Kembang Kuning, dan karyawan swasta. Warga perempuan mayoritas tidak bekerja, sebagai ibu rumah tangga.

Di Kembang Kuning Mulyo RT 16 terdapat sebuah balai pertemuan yang sudah berumur kurang lebih 30 tahun. Balai pertemuan tersebut sering disebut warga setempat sebagai Balai RT. Bangunan Balai Kembang Kuning Mulyo RT 16 berukuran $6 \mathrm{~m} \times 10 \mathrm{~m}$, dengan luas tanah $11 \mathrm{~m} \times 10$ m. Balai tersebut sudah bersertifikat atas nama milik warga RT 16 sehingga balai ini memang sudah selayaknya dimanfaatkan untuk keperluan warga. Kegiatan-kegiatan yang biasa dilakukan oleh warga Kembang Kuning Mulyo RT 16 di Balai RT adalah pertemuan warga, karang taruna, dan acara tasyakuran 17 Agustus. Sedangkan halaman Balai RT digunakan untuk kesenian memperingati 17 Agustus, tempat mengaji anak-anak, acara penyembelihan hewan kurban (Idul Adha), dan berkesenian bulan Muharram. Pemanfaatan Balai RT dipengaruhi oleh kapasitas dan kreatifitas warga serta pimpinan di Kembang Kuning Mulyo RT 16.

Untuk mewadahi aktifitas warga tersebut, diperlukan Balai RT yang layak sehingga dapat dimanfaatkan secara maksimal dan nyaman oleh warga. Seiring perkembangan waktu, Balai RT mengalami beberapa kerusakan karena sudah dimakan usia dan adanya alih fungsi dari penggunaan sebelumnya. Selama ini pengurus RT 16 hanya memanfaatkan iuran warga dan swadaya masyarakat untuk merenovasi Balai RT. Keterbatasan dana inilah yang membuat perbaikan Balai RT tidak maksimal dan secara fisik belum dapat dikatakan layak sebagai Balai RT. Renovasi yang sudah dilakukan pengurus adalah memasang sebagian keramik ruangan dalam, memasang plavon, dan menembok satu sisi halaman Balai RT. Masih banyak harapan pengurus RT terhadap kelayakan Balai RT, yaitu pavingisasi atau pengecoran halaman, pemasangan keramik lantai lanjutan pada bagian dalam ruangan, pemasangan keramik lantai pada teras, pengecatan ulang seluruh tembok dalam ruangan, dan perombakan mini taman sekeliling Balai RT.

Bagian luar ruangan Balai RT adalah bagian Balai RT yang paling sering digunakan oleh anak-anak untuk bermain dan mengaji. Namun kondisi teras masih berupa lantai semen yang retak dan berlubang, hal ini membahayakan keselamatan dan kesehatan anak-anak. Untuk kondisi sebagian lantai ruangan dalam Balai RT juga berlubang parah. Oleh sebab itu dipilih prioritas perbaikan yaitu melakukan renovasi lanjutan khususnya pemasangan keramik bagian dalam dan luar ruangan atau teras. Diharapkan dengan pemasangan keramik lantai di Balai RT akan meningkatkan rasa nyaman dan kreatifitas anak-anak atau warga saat melakukan aktivitas di Balai RT. Pemasangan keramik juga meningkatkan kesehatan dan keselamatan pengguna karena Balai RT akan lebih mudah dibersihkan, tidak lembab, dan tidak terkesan kumuh.

\section{Metode}

Kegiatan pengabdian masyarakat ini dilaksanakan di kampung Kembang Kuning Mulyo RT 16 RW 6, Kota Surabaya. Obyek sasaran utama adalah di Balai RT 16 RW 6, Kembang Kuning Mulyo IV, Kota Surabaya. Kegiatan pengabdian masyarakat dilaksanakan selama tiga bulan yaitu dari bulan Oktober sampai Desember 2019 dengan melibatkan partisipasi warga. Pelaksanaan program kegiatan pengabdian masyarakat dibagi dalam beberapa tahapan 
yaitu analisis situasi, persiapan, pelaksanaan program, monitoring dan evaluasi.

Pada tahap analisis situasi diawali dengan berdiskusi dengan pengurus RT 16. Didalam diskusi dibahas tentang pengumpulan informasi warga dan permasalahan yang terjadi di RT 16. Hasil diskusi menunjukkan bahwa permasalahan utama ada pada pembangunan Balai RT. Sehingga langkah selanjutnya adalah mendokumentasikan keseluruhan kondisi Balai RT dan memilih prioritas atas renovasi yang perlu dilakukan, yaitu pemasangan keramik lantai bagian dalam dan teras. Teknis dari pemasangan keramik juga didiskusikan bersama dengan pengurus RT.

Tahap persiapan dari kegiatan pengabdian ini adalah pengurus RT menginformasikan kegiatan renovasi Balai RT kepada warga sehingga warga dapat ikut berpartisipasi. Salah satu keterlibatan masyarakat terbatas pada orang yang mempunyai keterampilan sebagai tenaga bengunan, yaitu sebagai tukang atau pembantu tukang. Bahan-bahan pemasangan keramik dihitung oleh tim pengabdian, tukang, dan pengurus RT. Selanjutnya pembelian bahan-bahan dilakukan oleh tukang.

Dalam

pelaksanaannya, pemasangan keramik dilakukan sesuai dengan waktu yang telah disepakati bersama, berdasarkan jadwal kosong dari warga. Teknik pemasangan keramik masih menggunakan teknik pemasangan secara manual. Pemasangan keramik dimulai dari mengolah adonan semen sampai memberikan nat pada sisi keramik. Pemasangan keramik dilakukan oleh tukang, pembantu tukang, dan tim pengabdian.

Tahap monitoring dan evaluasi atas kegiatan dilakukan oleh tim pengabdian dan tukang. Tim dan tukang melihat semua kendala dan masalah yang muncul selama kegiatan pemasangan keramik berlangsung. Apabila terjadi masalah atau kendala, maka segera dicarikan solusi agar permasalahan segera teratasi. Evaluasi pelaksanaan pengabdian dan keberlanjutan program melibatkan pengurus RT dan tim pengabdian. Evaluasi dilakukan dengan memantau langsung dan mencatat kekurangan hasil pemasangan keramik meskipun kegiatan pemasangan telah selesai dilakukan.

\section{Hasil dan Pembahasan}

Pelaksanaan kegiatan pengabdian di kampung Kembang Kuning Mulyo dilakukan pada bulan Oktober sampai Desember, dari mulai perijinan secara administrasi sampai kegiatan telah selesai dilaksanakan. Kegiatan pengabdian masyarakat terpilih merupakan hasil diskusi dengan pengurus RT, yaitu renovasi lanjutan Balai RT terutama bagian pemasangan ubin keramik. Ubin lantai merupakan salah satu bahan bangunan yang digunakan dalam suatu bangunan. Menurut Hendra Baskara (2016) ubin digunakan agar lantai lebih nyaman digunakan dan terlihat lebih baik. Ada beberapa jenis lantai berdasarkan bahan pembentuknya, salah satunya adalah lantai keramik. Lantai keramik adalah bahan penutup lantai dari keramik. Keramik sendiri berasal dari bahan atau mineral yang terbuat dari tanah liat yang dibakar, bersifat keras, rapuh, tahan panas, dan tahan korosi serta mengandung satu atau lebih unsur logam termasuk oksigen (Tri Exaudi S., 2017). Kelebihan dari penggunaan lantai keramik adalah menambah kekuatan lantai, mempermudah pemeliharaan dan kebersihan lantai, mendekorasi lantai, dan menghadirkan atmosfer tertentu pada ruangan (A.G. Tamrin, 2008). Penggunaan, pengerjaan, dan perawatan keramik cukup mudah. Tidak membekas saat terkena cairan atau kotoran (Sopaster Stephen, dkk, 2016). Penentuan pemasangan keramik didukung oleh kondisi yang sebenarnya di Balai RT. Kondisi Balai RT 16 sebelum dilakukan pemasangan keramik dapat dilihat pada Gambar 1. Berdasarkan Gambar 1, lantai Balai RT sebelumnya hanya berupa lantai semen yang sudah 
retak dan berlubang, bahkan beberapa sudut lantai bagian dalam ruangan berupa tumpukan gragal.
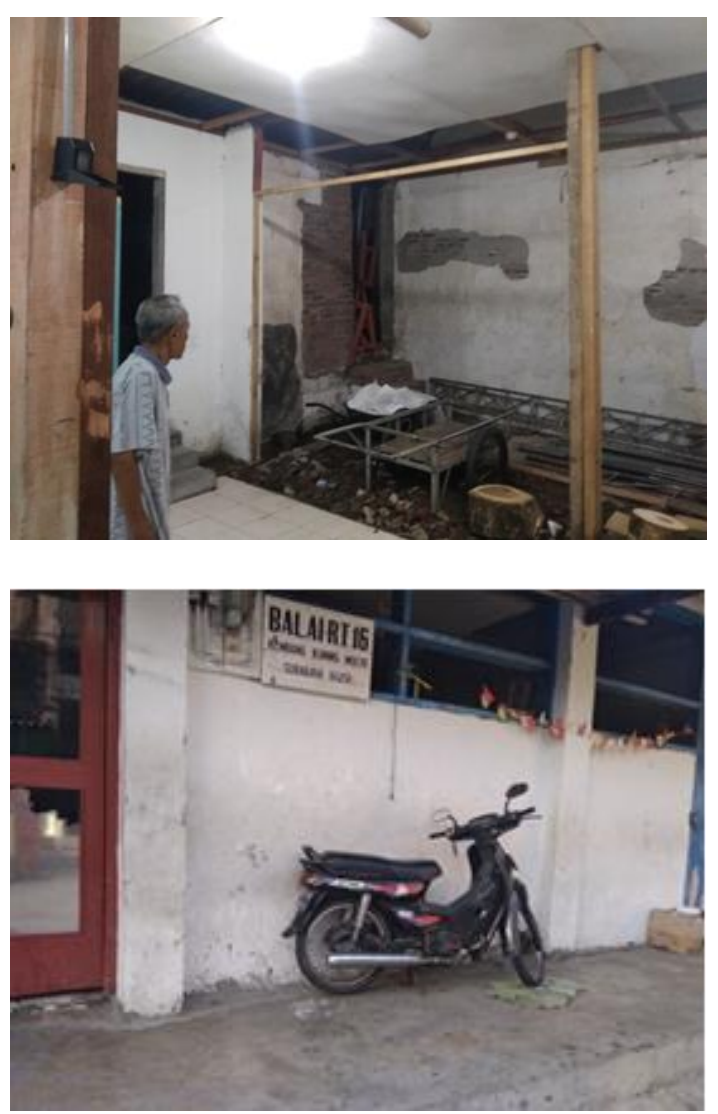

Gambar 1. Bagian Dalam Dan Luar Ruang Balai RT 16

Pemasangan lantai keramik dilaksanakan selama tiga hari oleh tim pengabdi dan warga yang memiliki keahlian dalam pertukangan. Selama tiga hari dilakukan dengan waktu terpisah berdasarkan jadwal kosong dari warga. Hari pertama dan kedua memasang keramik bagian dalam, kemudian hari ketiga memasang keramik bagian luar. Keramik yang digunakan khusus keramik lantai, berwarna putih dengan ukuran $30 \mathrm{x}$ $30 \mathrm{~cm}$. Permukaan keramik lantai sedikit berstruktur dan agak kasar, hal ini bertujuan supaya tidak licin dan orang yang melewati tidak terpeleset (Dyah Ayu Permata Hari, dkk, 2015). Langkah pemasangan keramik adalah memasang benang dari sudut ke sudut sebagai batas ketinggian keramik yang diharapkan. Sebelum keramik diaplikasikan ke lantai, terlebih dahulu keramik bagian bawah di kuas dengan air semen. Mengaplikasikan adonan semen dengan cetok secara merata pada dasar lantai, selanjutnya merekatkan keramik tersebut dengan tekanan disertai ketokan. Kelebihan adonan semen pada sisi keramik dibersihkan dengan spon basah. Langkah tersebut dilakukan untuk pemasangan keramik bagian dalam maupun luar ruangan Balai RT 16. Pelaksanaan kegiatan pengabdian dapat dilihat pada Gambar 2.
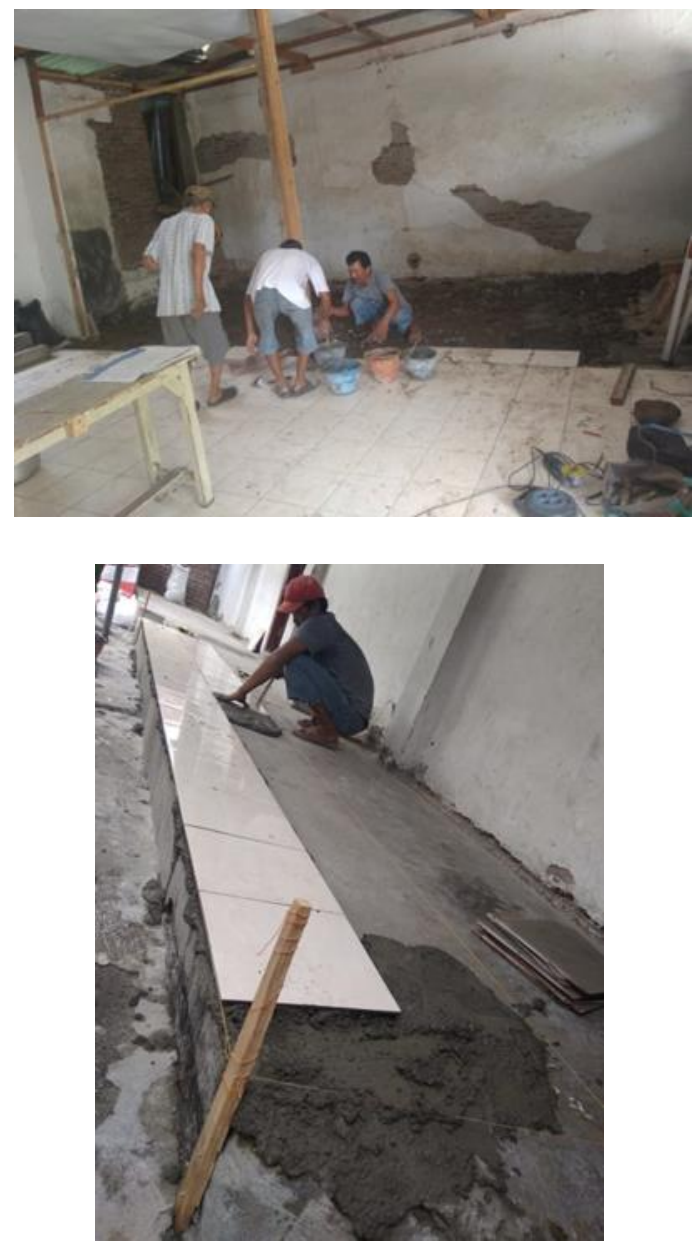

Gambar 2. Pemasangan Keramik Bagian Dalam Dan Luar Ruangan Balai RT

Hasil dari kegiatan pemasangan keramik di Balai RT adalah : (1) menambah kekuatan lantai Balai RT; (2) Balai RT lebih layak untuk digunakan warga; (3) lantai Balai RT mudah dibersihkan sehingga menunjang kesehatan ketika Balai RT digunakan; (4) pengurus lebih mudah memelihara lantai Balai RT; (5) menjaga keselamatan pengguna karena lantai tidak menjadi licin; (6) memperindah penampilan ruangan Balai RT. 
Dalam pelaksanaan kegiatan pengabdian terjadi beberapa hambatan. Hambatan dalam pelaksanaan pengabdian masyarakat ini berkaitan dengan cuaca yang kurang mendukung. Hambatan pertama adalah terjadi hujan ketika tukang mengolah adonan semen. Hal ini menyebabkan tukang harus segera memindahkan adonan semen dari halaman ke teras Balai RT. Selama hujan berlangsung, tukang melakukan pengadukan semen di teras Balai RT dengan luasan teras yang tidak terlalu lebar. Ketika hari kedua akan mengerjakan pemasangan keramik bagian dalam, tim dihadapkan pada masalah bahwa air meresap keluar dari sela-sela keramik dekat dengan tembok kamar mandi. Hal ini disebabkan oleh curah hujan yang deras masuk melalui pipa pembuangan kamar mandi. Air hujan memenuhi kamar mandi padahal kondisi sudut-sudut antara lantai kamar mandi dan tembok kamar mandi kurang merekat sempurna. Solusi dari air meresap keluar adalah menutup sela-sela lantai kamar mandi dan tembok kamar mandi yang tidak melekat sempurna dengan adonan semen. Selanjutnya membongkar ulang beberapa keramik ruangan Balai RT yang dekat tembok kamar mandi dan menutup sela-sela tembok dengan adonan semen kemudian keramik dipasang kembali. Selama kegiatan pengabdian berlangsung, tim beserta tukang selalu memonitoring pemasangan keramik karena banyak peluang untuk hambatan teknis terjadi selama pengabdian berlangsung.

Setelah kegiatan pengabdian telah dilaksanakan tim beserta pengurus RT melakukan evaluasi. Pelaksanaan evaluasi berupa diskusi antara pengurus RT dan tim pengabdian untuk mengetahui sejauh mana keramik terpasang sempurna terutama dimusim penghujan. Dari evaluasi juga dapat diperoleh informasi segala kendala teknis yang menyertai kegiatan pengabdian karena kekurangan-kekurangan kondisi Balai RT yang perlu ditindaklanjuti.

\section{Simpulan}

Kegiatan pengabdian dilakukan di Balai RT 16 RW 6, Kembang Kuning Mulyo Kota Surabaya. Pengabdian berupa pemasangan keramik pada lantai bagian dalam dan luar ruangan (teras). Sebelumnya lantai Balai RT 16 masih berupa lantai semen yang lembab, retak, dan beberapa sudut berlubang. Sejak dilakukan pemasangan keramik, lantai Balai RT 16 terlihat lebih bersih, layak digunakan, kuat, dan tidak lembab. Disamping itu anak-anak dan anggota karang taruna dapat lebih leluasa dalam menggunakan teras Balai RT untuk berkegiatan. Kegiatan pengabdian didukung penuh oleh warga terbukti dengan keikutsertaan warga pada kegiatan pemasangan keramik dan pemahaman mereka untuk turut menjaga kondisi Balai RT yang sudah lebih baik.

\section{Daftar Pustaka}

Baskara, Hendra. (2016). Tinjauan Karakteristik Dan Kekuatan Ubin / Tegel Lantai Yang Menggunakan Agregat Pecahan Genteng. Prosiding Seminar Nasional Teknik Sipil 2016, hlm. 425430. ISSN: 2459-9727.

Budiharjo, Eko. (1997). Sejumlah Masalah Perkampungan Kota. Bandung: Alumni.

Hari, Dyah Ayu Permata, Indyah Martiningrum, dan Ali Soekirno. (2015). Perancangan Kembali Pasar Setonobetek Kota Kediri (Penerapan Pola Tata Ruang Dan Pemilihan Material Yang Mengacu Pada Peraturan Pasar Sehat), Jurnal Mahasiswa Jurusan Arsitektur, 3(1), 113.

JC, Turner. (1985). Housing by People. London: MIT Press.

KBBI. Kamus Besar Bahasa Indonesia [Online]. Diunduh dari: https://kbbi.web.id/pusat, 20 Desember 2019.

Sidabutar, Tri Exaudi. (2017). Pembuatan Dan Karakterisisasi Keramik Magnesium Alumina Silika Dari Abu Vulkanik Gunung Sinabung. Jurnal Teknik Mesin (JTM), 6(1), 28-35.

Stephen, Sopater, IGN. Ardana, dan Grace Mulyono. (2016). Perancangan Interior 
23 | Desrina Yusi Irawati, dkk : Penyiapan lantai balai kampung...

Honda CBR Cluan Surabaya. Jurnal Intra, 4(2), 808-813.

Tamrin, A.G. (2008). Teknik Konstruksi Bangunan Gedung Jilid 1. Jakarta: Direktorat Pembinaan Sekolah Menengah Kejuruan. Direktorat Jenderal Manajemen Pendidikan Dasar dan Menengah. Departemen Pendidikan Nasional. 